\title{
Causality Between Market Liquidity and Depth for Energy and Grains
}

\author{
Ramazan Sari \\ Department of Business Administration, \\ Middle East Technical University \\ Ankara, Turkey \\ Shawkat Hammoudeh \\ Lebow College of Business \\ Drexel University \\ Philadelphia, PA, USA \\ Chia-Lin Chang \\ Department of Applied Economics \\ Department of Finance \\ National Chung Hsing University \\ Taichung, Taiwan \\ Michael McAleer \\ Econometric Institute \\ Erasmus School of Economics \\ Erasmus University Rotterdam \\ and \\ Tinbergen Institute \\ The Netherlands \\ and \\ Department of Quantitative Economics \\ Complutense University of Madrid
}

April 2011

*For financial support, the third author wishes to thank the National Science Council, Taiwan, and the fourth author wishes to thank the Australian Research Council, National Science Council, Taiwan, and the Japan Society for the Promotion of Science. 


\begin{abstract}
This paper examines the roles of futures prices of crude oil, gasoline, ethanol, corn, soybeans and sugar in the energy-grain nexus. It also investigates the own- and cross-market impacts for lagged grain trading volume and open interest in the energy and grain markets. According to the results, the conventional view, for which the impacts are from oil to gasoline to ethanol to grains in the energy-grain nexus, does not hold well in the long run because the oil price is influenced by gasoline, soybeans and oil. Moreover, gasoline is preceded by only the oil price and ethanol is not foreshadowed by any of the prices. However, in the short run, two-way feedback in both directions exists in all markets. The grain trading volume effect across oil and gasoline is more pronounced in the short run than the long run, satisfying both the overconfidence/disposition and new information hypotheses across markets. The results for the ethanol open interest shows that money flows out of this market in both the short and long run, but no results suggest across market inflows or outflows to the other grain markets.
\end{abstract}

Keywords: Causality, market liquidity, depth, energy, grains. JEL Classifications: Q11, Q18, Q42 


\section{Introduction}

Food prices, particularly grain prices, have risen significantly in the last few years and led to political protests in developing countries. The prevailing view considers carnivores in countries like China and India, droughts in Russia and Eastern Europe, or heavy rain in North America, as the culprits behind the rising trend in grain prices. The countervailing view considers the real culprits to be increases in consumption of ethanol and other bio-fuels which, through the derived demand, have led to increases in prices of these goods in the supply chain, in reaction to higher oil prices. Some analysts view the use of commodities by financial investors (the so-called "financialization of commodities") as partly responsible for the recent price spike (Baffes and Haniotis, 2010). Such a view gives an important role to hedgers and speculators.

The direction of the underlying price causality in the countervailing view emanates first from high crude oil, which is then filtered through gasoline to increases in the price of ethanol. As ethanol in the USA is derived from corn, higher ethanol prices cause spikes in corn prices which, in turn, though plant acreage sharing, influences the prices of soybeans and sugar (Lin and Riley, 1998). This is the conventional energy route to grains. However, is it possible that spikes in grain prices, particularly corn, could lead to surges in ethanol prices, gasoline and crude

oil? These are all commodities and are influenced by macroeconomic variables. Additionally, there is complementarity and/or substitutability between corn and soybeans and between corn and sugar, all of which share the planted acreage (Takgoz et al., 2008). Moreover, corn-based ethanol is a substitute for gasoline and can serve as the link in the causation between petroleum and grains. In fact, some agricultural economists consider ethanol as the catalyst that closely links energy and agricultural products since the ethanol boom that started in 2006 (Tyner, 2008). 
These possible causal relationships, regardless of where they might start and end, are affected by the financialization of commodities. Financial investors can affect not only the direction of causality but also the number and intensity of such interrelationships. Market tradability and depth (Kyle, 1985), as reflected in the sizes of trading volumes and open interest decided by hedgers, speculators and arbitrageurs, can play a role in such interrelationships (Franken and Parcell, 2003; Dahlgran 2009). Trading volume is important in improving forecasts of changes in futures prices. The price-trading volume, or open interest relation, is important for several reasons, as it: provides insights as to the structure of markets (such as the dominance of speculators and the presence of hedging and arbitrage activity; is used in event studies; shows the importance of private and public information in determining investor demand (Admati and Pfleideter, 1988); and is crucial to the debate regarding the distribution of speculative prices

Some markets, such as that for ethanol, are known to be thin, and hence are avoided by hedgers and speculators. For this reason, it will be interesting to explore and compare the trading volume and open interest of these markets on own- and cross-returns.

The objectives of this paper are four-fold, namely to: (1) discern the forcing variables that affect the long-run relationships among the futures prices of crude oil, gasoline, ethanol, corn, soybeans and sugar; (2) determine if ethanol plays a linkage role between petroleum and grain products; (3) analyze the long- and short-run relationships between these products; and (4) examine the roles that the grain trading volume and open interest play in the petroleum-grain interrelationships.

The paper is organized as follows. Section 2 provides a review of the literature, Section 3 presents the data and descriptive statistics of the 12 series used in the empirical analysis, Section 4 presents the models and empirical results, and Section 5 gives some concluding comments. 


\section{Review of the Literature}

The early literature has investigated the cointegrating relationships between spot and futures prices for most of commodities considered in this paper. Garbade and Silber (1982) examined the price movements and price discovery function in the spot and futures markets for seven storable commodities, including corn, wheat, oats, orange juice, copper, gold and silver. Their findings indicated that, in general, futures dominate spot price changes for most of these commodities. Their evidence suggested that, for 70 percent of new information, the futures market dominates the spot markets for corn, wheat and orange juice. The authors obtained a similar result for gold, but the pricing power for silver, oats and copper was more divided between the spot and futures market.

Yang et al. (2001) examined the price discovery function for storable (namely, corn. oats, soybeans, wheat, cotton and pork bellies) and non-storable (namely, hogs, live cattle, feeder cattle) commodities. They found that although, in general, storability does not affect the futures price discovery function, futures contracts can be used as a price discovery tool in all of these markets. They also found that large differences in the trading volumes of these commodities had little effect on the predictive power of futures prices.

Wang and Ke (2002) assessed the long- and short-run efficiency of Chinese wheat and soybean futures and spot prices, with different maturities for the futures contracts. Their findings implied that there exists a long-run relationship between futures and spot prices for soybean in China, while the short-run lead/lag relationship is weak. However, wheat futures contracts were found to be inefficient, possibly due to government intervention in the wheat market. 
Zapato et al. $(2003,2005)$ examined cointegration between the New York futures price and the Dominican Republic spot price for sugar. Their empirical evidence suggested that the World Futures Sugar (WFS) price has predictive power for the spot price of a small sugar-producing country. It was found that, in general, futures prices appeared to play a dominant role in the price discovery mechanism. However, there appeared to be neither long-run relationships nor shortrun leads in these tightly-traded markets.

Mattos and Garcia (2004) investigated the relationships between spot and futures prices in six Brazilian agricultural markets (namely, Arabic coffee, corn, cotton, live cattle, soybeans and sugar). All of these markets are considered to be thinly traded in terms of trading volume, compared with those in the USA. The paper has two surprising results relative to those of the US markets: (1) the thinly-traded sugar futures contracts showed evidence of some degree of longrun relationships (cointegration), with the futures price playing the dominant role; (2) the highlytraded corn contracts showed almost no interrelations between the futures and cash prices. However, both the Brazilian sugar and corn markets have peculiarities that may account for these surprising results.

Tyner (2010) explored the integration of energy and agricultural markets, and addressed the evolving relationships among the prices of crude oil, gasoline, ethanol and corn. It was found that there is little correlation between these prices before 2005. However, a strong link emerged between oil, gasoline and corn in the ethanol boom period of 2006-2008, but with no relationship between the prices of ethanol and corn. However, the relationship between the prices of ethanol and corn strengthened in late-2008 and 2009 as ethanol production came under severe pressure, leading to a causal relationship originating from corn to ethanol prices. 
Gohin and Treguer (2010) developed a partial equilibrium model, focusing on ethanol production with downside risk-averse corn farmers. The objective was to assess the impact of ethanol production on agricultural volatility, particularly corn. The empirical results showed substantial ethanol impact on the distribution of corn prices. Risk-adverse corn farmers can still benefit due to the higher mean price effect, despite increases in the corn price variance.

Using a multi-commodity, multi-county partial equilibrium model to examine the impact of the expanded US ethanol production on planted acreage crop prices, livestock production and retail food prices, Tokgoz et al. (2008) found that expanded ethanol production would increase the long-run prices of both crops and livestock, with the increase in livestock being greater. The authors also indicated that an increase in the price of oil would lead to an expansion of the US ethanol sector.

Balcombe and Rapsomanikis (2008) developed a range of generalized bivariate errorcorrection models to explore the nonlinear long-run price relationships in the sugar-ethanol-oil nexus. The models were estimated using the Bayesian Monte Carlo Markov Chain method. The estimates suggested that the long-run drivers of the Brazilian sugar prices are oil prices. The price adjustments were non-linear and causal from oil prices to sugar and ethanol prices, but were linear between ethanol and sugar prices.

Although the specific results were mixed, as indicated above, Dahlgran (2009) investigated the relationship between ethanol futures contracts, which are thinly traded, and gasoline futures contracts, which are tightly trade. The evidence suggested that the former has hypothetically superior price risk hedging capabilities than the latter because ethanol swaps add depth to its futures market. 
The approach adopted in this paper distinguishes between the forcing and dependent variables in the energy-grain nexus, which includes oil, gasoline, ethanol, corn, soybeans and sugar. It also seeks to use the ARDL technique to circumvent the problem of having an $\mathrm{I}(0)$ process for the trading volumes in a setting where virtually all of the other variables are I(1). This technique enables us to test the significance of market liquidity and depth on returns. As discussed above, some studies have suggested that some markets, such as for ethanol, are avoided by hedgers and speculators as it is "too thin". This proposition will be examined below.

\section{Data and Descriptive Statistics}

This paper uses daily time series data on the closing futures prices of six differently traded and closed linked energy and agricultural commodities, specifically crude oil, gasoline, bio-fuel ethanol, corn, soybeans and sugar. The data set also includes measures of market liquidity and depth for the three grain products, which are considered exogenous variables in the employed models. These six measures include trading volume (VM) and open interest (OI) for ethanol, soybeans and sugar. Overall, this study has 12 variables.

Volume characterizes the total amount of trading activity or contracts that have changed hands in a given commodity market for a single trading day. The greater is the amount of trading, the higher will be the trading volume. Thus, volume represents a measure of intensity or pressure behind a price trend. The greater is the volume, the more likely will the existing trend persist. Technicians have the view that volume precedes price, thereby suggesting that the loss of upside price pressure in an uptrend, or downside pressure in a downtrend, will be captured in the volume before presenting itself as a reversal in trend. 
Open Interest is the total number of outstanding contracts that are held by market participants at the end of each day. While the trading volume measures the pressure or intensity behind a price up or down trend, open interest measures the flow of money into the futures market. Therefore, a seller and a buyer combine to create only one contract. In order to determine the total open interest for any given market, one needs only to know the totals from one side or the other, buyers or sellers, not the sum of both. Increasing open interest implies that new money is flowing into the marketplace, so that the present trend (up, down or sideways) will persist. Declining open interest means that the market is liquidating, and hence implies that the prevailing price trend is ending. A leveling of steadily increasing open interest following a sustained price advance is often an early warning of the end to an uptrending or bull market.

The sample covers the period May 31, 2006 - January 13, 2011. The length of this period was dictated by the availability of data on ethanol futures trading in the United States.

The ethanol futures price is sourced from Thompson Reuters and is expressed in US dollars per gallon. Data on the ethanol futures price are for ethanol traded on eCBOT. Its class is CZE and is expressed in US dollars per bushel wheat (BW). Data on corn futures are sourced from Datastream for the US market. The corn futures class is CC, trades at CBOT, and is expressed in dollars per bushel. The futures soybean trades at CBOT, its price is expressed in dollars per bushel, and the class is CS. The futures sugar is sugar \# 11 (class NSB), is expressed in dollars per pound, and trades at the New York Board of Trade (NYBOT). Crude oil is the West Texas Intermediate (WTI) three-month futures traded at the New York Mercantile Exchange (NYMEX), and RBOB is the three-month gasoline trades at the New York Harbor Exchange. 
Both oil and gasoline prices are dollars per gallon as we transformed the oil barrels to gasoline to be consistent with the gasoline gallons.

The descriptive statistics for the endogenous returns of the six energy and agricultural commodity futures prices, and the six returns for the exogenous trading volume and open interests for ethanol, soybeans and sugar, are given in Table 1. The highest mean return over the sample period is for soybeans, followed by corn (Table 1 - Panel A). The relatively high return for corn reflects rising oil and ethanol prices, and a targeted government policy aimed at promoting corn-based ethanol production to be progressively used as an additive to conventional gasoline. An increase in demand for corn also comes from carnivores in countries like China and India, and climate change drought.

\section{[Table 1 goes here]}

It is not surprising that ethanol has a negative return over this period. Tyner (2010) found that in late 2008 and 2009 ethanol production came under severe pressure because of excess capacity after the collapse of oil prices from $\$ 147$ a barrel in July 2008 to $\$ 32$ in March 2009. About two billion of the 12 billion gallons of ethanol capacity were shut down.

In terms of volatility, as defined by the standard deviation, soybean and corn have the highest volatility, while ethanol has volatility similar to that of oil, gasoline and sugar. This result probably reflects differences in market thinness and contract specifications for these commodities. Ethanol has its peculiarities, such as tax credit, government production mandate and blend wall constraints. These factors may account for the relatively low volatility in ethanol.

The returns have different degrees of skewness. Interestingly, all the agricultural and energy returns are skewed to the left, indicating that these futures series have longer left tails (extreme 
losses) than right tails (extreme gains). This stylized fact should be of interest to participants in commodity markets.

All of the price distributions have kurtosis that is significantly higher than 3 , implying that higher probabilities of extreme market movements in either direction (gains or losses) occur in these futures markets, with greater frequency in practice than would be predicted by the normal distribution. The highest kurtosis is for ethanol, followed by soybeans, while the lowest is for corn, followed by gasoline and crude oil. The Jarque-Bera Lagrange multiplier statistics confirm non-normal distributions in all the return series.

If we examine the market depth of the agricultural products, as measured by percentage changes in open interest, it is found that soybeans have the highest historical (anecdotal) depth, followed by corn and sugar (Table 1- Panel B). Ethanol has a meager percentage change in open interest and is presently just a $10 \%$ additive to RBOB gasoline. This anecdotal evidence confirms the view that hedgers and speculators avoid the ethanol futures market (Dahlgran, 2009). The open interest for all the gain variables is extremely volatile relative to the futures prices. Corn has the highest open interest volatility, while ethanol, with a shallow market, has the least open interest volatility. Analogously, corn has the highest trading volume and ethanol has the lowest. Trading volume is much more volatile than open interest, which is not surprising. As is the case with open interest, corn has the highest trading volume volatility and ethanol has the lowest.

The ADF and Phillips-Perron (PP) tests are used to check the stationarity of these variables under both the constant and constant plus trend specifications. Table 2 displays the results. The ADF and PP tests show that trading volumes are $\mathrm{I}(0)$ while open interests are $\mathrm{I}(1)$. The futures prices are I(1), with the exception of the futures price for ethanol, which shows mixed results. 
These mixed unit roots make the ARDL approach an ideal technique for estimating this system without excluding any variables based on the outcome of the stationarity tests.

\section{[Table 2 goes here]}

\section{Empirical Model and Results}

We use the ARDL approach developed in Pesaran and Pesaran (1997), and Pesaran, Shin and Smith (2001) for the system of six endogenous energy and grains futures prices, and six exogenous trading volumes and open interests for the grain commodities. As indicated above, the ARDL approach has several advantages over other well-known cointegration methods. First, the ARDL approach does not require the order of integration for the series to be the same or be I(1), as is the case in the Johansen and Engle-Granger cointegration methods. The order of any series in the ARDL methodology is only needed to identify the critical values for purposes of inference. Second, with the ARDL method it is possible to determine more efficient cointegrating relationship(s) than in the other methods, even if the sample size is very small (Ghatak and Siddiki, 2001). A third advantage is that an error-correction model can be derived through a simple linear transformation. Finally, the ARDL method overcomes the problems resulting from the series with unit roots (Laurenceson and Chai, 2003). For instance, Stock and Watson (2003) report that if a regressor has a unit root, then the OLS estimator of its coefficient and the corresponding t-statistics from OLS estimation can have non-normal distributions. This problem leads to spurious regressions and autoregressive coefficients that are biased towards zero.

As a first step, we test for cointegrating relationships among the variables by employing the bounds testing procedure (Pesaran and Pesaran, 1997; Pesaran, Shin and Smith, 2001) within an 
ARDL framework. This procedure assists in identifying the long-run relationship by positing a dependent variable determined by its forcing variables. As we do not have any prior information regarding the directions of the long-run relationships among the energy-grain prices, we will construct the unrestricted regressions as follows:

$$
\begin{aligned}
& \Delta L F S B_{t}=a_{S B}+b_{S B} \omega_{t}+ \\
& \sum_{i=1}^{n} c_{i S B} \Delta L F S B_{t-i}+\sum_{i=1}^{n} d_{i S B} \Delta L F S_{t-i}+\sum_{i=1}^{n} e_{i S B} \Delta L F O_{t-i}+\sum_{i=1}^{n} f_{i S B} \Delta L F G_{t-i}+\sum_{i=1}^{n} g_{i S B} \Delta L F E_{t-i}+\sum_{i=1}^{n} h_{i S B} \Delta L F C_{t-i} \\
& +\lambda_{I S B} L F S B_{t-1}+\lambda_{2 S B} L F S_{t-1}+\lambda_{3 S B} L F O_{t-1}+\lambda_{4 S B} L F G_{t-1}+\lambda_{S S B} L F E_{t-1}+\lambda_{6 S B} L F C_{t-1}+\varepsilon_{S B t}
\end{aligned}
$$

$$
\begin{aligned}
& \Delta L F S_{t}=a_{S}+b_{S} \omega_{t}+ \\
& \sum_{i=1}^{n} c_{i S} \Delta L F S B_{t-i}+\sum_{i=1}^{n} d_{i S} \Delta L F S_{t-i}+\sum_{i=1}^{n} e_{i S} \Delta L F O_{t-i}+\sum_{i=1}^{n} f_{i S} \Delta L F G_{t-i}+\sum_{i=1}^{n} g_{i S} \Delta L F E_{t-i}+\sum_{i=1}^{n} h_{i S} \Delta L F C_{t-i} \\
& +\lambda_{I S} L F S B_{t-1}+\lambda_{2 S} L F S_{t-1}+\lambda_{3 S} L F O_{t-1}+\lambda_{4 S L} L F G_{t-1}+\lambda_{S S} L F E_{t-1}+\lambda_{6 S} L F C_{t-1}+\varepsilon_{S t}
\end{aligned}
$$

$$
\begin{aligned}
& \Delta L F O_{t}=a_{O}+b_{O} \omega_{t^{+}} \\
& \sum_{i=1}^{n} c_{i o} \Delta L F S B_{t-i}+\sum_{i=1}^{n} d_{i o} \Delta L F S_{t-i}+\sum_{i=1}^{n} e_{i O} \Delta L F O_{t-i}+\sum_{i=1}^{n} f_{i O} \Delta L F G_{t-i}+\sum_{i=1}^{n} g_{i O} \Delta L F E_{t-i}+\sum_{i=1}^{n} h_{i O} \Delta L F C_{t-i} \\
& +\lambda_{I O} L F S B_{t-1}+\lambda_{2 O} L F S_{t-1}+\lambda_{3 O} L F O_{t-1}+\lambda_{4 O} L F G_{t-1}+\lambda_{5 O} L F E_{t-1}+\lambda_{6 O} L F C_{t-1}+\varepsilon_{O t}
\end{aligned}
$$




$$
\begin{aligned}
& \Delta L F G_{t}=a_{G}+b_{G} \omega_{t}+ \\
& \sum_{i=1}^{n} c_{i G} \Delta L F S B_{t-i}+\sum_{i=1}^{n} d_{i G} \Delta L F S_{t-i}+\sum_{i=1}^{n} e_{i G} \Delta L F O_{t-i}+\sum_{i=1}^{n} f_{i G} \Delta L F G_{t-i}+\sum_{i=1}^{n} g_{i G} \Delta L F E_{t-i}+\sum_{i=1}^{n} h_{i G} \Delta L F C_{t-i} \\
& +\lambda_{1 G} L F S B_{t-1}+\lambda_{2 G} L F S_{t-1}+\lambda_{3 G} L F O_{t-1}+\lambda_{4 G} L F G_{t-1}+\lambda_{5 G} L F E_{t-1}+\lambda_{6 G} L F C_{t-1}+\varepsilon_{G t}
\end{aligned}
$$

$$
\begin{aligned}
& \Delta L F E_{t}=a_{E}+b_{E} \omega_{t}+ \\
& \sum_{i=1}^{n} c_{i E} \Delta L F S B_{t-i}+\sum_{i=1}^{n} d_{i E} \Delta L F S_{t-i}+\sum_{i=1}^{n} e_{i E} \Delta L F O_{t-i}+\sum_{i=1}^{n} f_{i E} \Delta L F G_{t-i}+\sum_{i=1}^{n} g_{i E} \Delta L F E_{t-i}+\sum_{i=1}^{n} h_{i E} \Delta L F C_{t-i} \\
& +\lambda_{I E} L F S B_{t-1}+\lambda_{2 E} L F S_{t-1}+\lambda_{3 E} L F O_{t-1}+\lambda_{4 E} L F G_{t-1}+\lambda_{5 E} L F E_{t-1}+\lambda_{6 E} L F C_{t-1}+\varepsilon_{E t}
\end{aligned}
$$

$$
\begin{aligned}
& \Delta L F C_{t}=a_{C}+b_{C} \omega_{t}+ \\
& \sum_{i=1}^{n} c_{i C} \Delta L F S B_{t-i}+\sum_{i=1}^{n} d_{i C} \Delta L F S_{t-i}+\sum_{i=1}^{n} e_{i C} \Delta L F O_{t-i}+\sum_{i=1}^{n} f_{i C} \Delta L F G_{t-i}+\sum_{i=1}^{n} g_{i C} \Delta L F E_{t-i}+\sum_{i=1}^{n} h_{i C} \Delta L F C_{t-i} \\
& +\lambda_{1 C} L F S B_{t-1}+\lambda_{2 C} L F S_{t-1}+\lambda_{3 C} L F O_{t-1}+\lambda_{4 C} L F G_{t-1}+\lambda_{5 C} L F E_{t-1}+\lambda_{6 C} L F C_{t-1}+\varepsilon_{O t}
\end{aligned}
$$

where the vector $\omega_{t}=\left\{L 1 L V M S B_{t}, L 1 L V M S_{t}, L_{1 L V M E}, L_{t} L V V M C_{t}, L 1 L O I S B_{t}, L_{1 L O I S}\right.$, LILOIE $_{t}$, LILOIC $\left._{t}\right\}$ denotes lagged trading volumes and open interest for soybeans, sugar, ethanol and corn. In the above equations, $S B$ is the futures price for soybean, $F S$ is the futures price for sugar, $F O$ is the futures price for West Texas Intermediate (WTI), $F G$ is the futures price for RBOB gasoline, $F E$ is the futures price for bio-fuel ethanol, and $F C$ is the futures price 
for corn. All the price, trading volume and open interest variables are expressed as natural logarithms of the levels.

In the equations, the parameters $c, d, e, f, g$, and $h$ denote the short-run coefficients and the $\lambda$ denote the long-run multipliers of the underlying ARDL model. The null hypothesis of "no cointegration" in each equation is that $\lambda_{1}=\lambda_{2}=\lambda_{3}=\lambda_{4}=\lambda_{5}=\lambda_{6}=0$. The general F-statistics are used to test the hypotheses. The calculated F statistics are compared with the critical values obtained from Pesaran, Shin and Smith (2001) and Pesaran and Pesaran (2009). Two types of critical values are provided. The upper level critical values are tabulated for the assumption that all the series are integrated of order one, I(1), while the lower level critical values are tabulated for the assumption that all the series are integrated of order zero, I(0). If the orders of the series are mixed, then the calculated F-statistics are compared with the corresponding upper and lower level critical values. For two possible cases the results are conclusive. One case is that the null of "no cointegration" cannot be rejected if the test statistic for the variables falls below the lower

critical value, while the other case is that the no cointegration null hypothesis will be rejected if the statistic is greater than the upper level critical value. If the statistic lies between the lower and upper bounds, the test result is inconclusive (Pesaran and Pesaran, 1997).

\section{Empirical Results}

The calculated F-statistics for the cointegration relationships are presented in Table 3. The optimal lag suggested by the LR test is six. The results suggest that there are three cointegrating vectors for the six endogenous variables. The first cointegrating vector indicates that sugar, soy beans, gasoline, ethanol and corn prices are forcing variables of the oil price, which is more in 
line with the prevailing carnivores view. The second vector reveals that sugar, soy beans, oil, ethanol and corn prices are the forcing variables of the gasoline prices, which is also in line with the carnivores view. The third vector shows that all the other variables in the system are forcing variables of the ethanol prices.

\section{[Table 3 goes here]}

The long-run relationships are estimated using the following specified ARDL $(k, l, m, p, r, s)$ models. Before estimation of the models, the orders of the lags $(k, l, m, p, r, s)$ in the ARDL models must be selected ${ }^{1}$ using the Akaike Information Criterion (AIC) and the Schwartz Bayesian Criterion (SBC). The SBC selects the smallest possible lag length, while AIC selects the maximum relevant lag length (Pesaran and Pesaran, 1997) ${ }^{2}$. We restrict our long-run coefficient estimates and the error-correction models with the presence of the cointegrating relationships (see Table 3):

$$
\begin{aligned}
& L F O_{t}=a_{O}+b_{O} \omega_{t}+ \\
& \sum_{i=0}^{k} \alpha_{i O} \Delta L F S B_{t-i}+\sum_{i=0}^{l} \beta_{i O} \Delta L F S_{t-i}+\sum_{i=1}^{m} \delta_{i O} \Delta L F O_{t-i}+\sum_{i=0}^{p} \phi_{i O} \Delta L F G_{t-i}+\sum_{i=0}^{r} \gamma_{i O} \Delta L F E_{t-i}+\sum_{i=0}^{s} \eta_{i O} \Delta L F C_{t-i} \\
& +u_{T o} \\
& L F G_{t}=a_{G}+b_{G} \omega_{t}+ \\
& \sum_{i=0}^{k} \alpha_{i G} \Delta L F S B_{t-i}+\sum_{i=0}^{l} \beta_{i G} \Delta L F S_{t-i}+\sum_{i=0}^{m} \delta_{i G} \Delta L F O_{t-i}+\sum_{i=1}^{p} \phi_{i G} \Delta L F G_{t-i}+\sum_{i=0}^{r} \gamma_{i G} \Delta L F E_{t-i}+\sum_{i=0}^{s} \eta_{i G} \Delta L F C_{t-i} \\
& +u_{t G} \\
& \text { } \\
& { }^{1} \text { See Appendix in Pesaran and Pesaran (2009) for the technical explanation of the ARDL approach. } \\
& { }^{2} \text { The ARDL results based on the SBC are similar to those based on AIC. Thus, we report results based on AIC only. } \\
& \text { The SBC results are available on request. }
\end{aligned}
$$

\footnotetext{
${ }^{1}$ See Appendix in Pesaran and Pesaran (2009) for the technical explanation of the ARDL approach.

${ }^{2}$ The ARDL results based on the SBC are similar to those based on AIC. Thus, we report results based on AIC only. The SBC results are available on request.
} 
$L F E_{t}=a_{E}+b_{E} \omega_{t}+$

$\sum_{i=0}^{k} \alpha_{i E} \Delta L F S B_{t-i}+\sum_{i=0}^{l} \beta_{i E} \Delta L F S_{t-i}+\sum_{i=0}^{m} \delta_{i E} \Delta L F O_{t-i}+\sum_{i=0}^{p} \phi_{i E} \Delta L F G_{t-i}+\sum_{i=1}^{r} \gamma_{i E} \Delta L F E_{t-i}+\sum_{i=0}^{s} \eta_{i E} \Delta L F C_{t-i}$

$+u_{t E}$

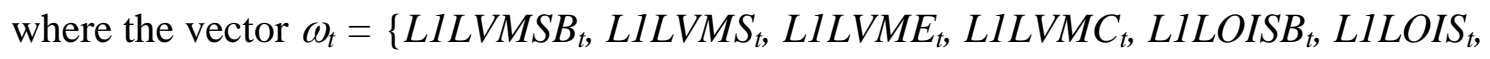
LILOIE $_{t}$, LILOIC $\left._{t}\right\}$, as indicted above.

The long-run results for the crude oil price equation are reported in Table 4. These results demonstrate that the impacts of gasoline and soybean prices on oil prices are positive and significant in the long-run. This long-run causality order runs counter to the conventional view which posits that the lead comes from oil prices. This empirical result could, in fact, reflect generally the impact of the long-run macroeconomic factors, such as rising inflation, booming economy and rising standards of living on the derived demands. However, the impact of the corn price on the crude oil price is negative and significant in the long run, which is likely to be capturing the conversion of corn to ethanol in the distant horizon.

The oil price also adjusts downward in reaction to increases in the intensity of the trading volumes in the ethanol market in the long run. This cross-market trading volume pressure coming from the ethanol market seems to induce a price reversal in the oil market, possibly because of preference/disposition shocks. This negative impact of the ethanol lagged trading volume would seem to be consistent with the irrationally cross-market liquidity hypothesis.

\section{[Table 4 goes here]}


The short-run dynamics for the oil price are provided in Table 5. It seems the burden of short-run adjustments in oil prices is influenced by all the endogenous variables, as well as by the lagged trading volumes of ethanol and soybeans, namely $V M E$ and $V M S B$. The trading volume for ethanol has a negative impact on the oil price, while that of soybeans has a positive influence. As indicated above, the negative impact is consistent with the irrationally cross-market liquidity. This finding is consistent with similar volume results for stock markets.

\section{[Table 5 goes here]}

The second result for the short-run positive adjustment for the oil price seems to be consistent with the results for informational trading, which hypothesize that all new information hits prices and volume in the same way. Overall, the estimates of this oil price equation imply that cross-market liquidity overrides cross-market depth, as far as the oil market is concerned, and that none of the open interest $(O I)$ is significant, which means that no new money flows to the oil market from the other markets in the short run. On the other hand, the impacts of volume trading and open interest of corn and sugar on oil prices are opaque. Weakness or lack of significance of the trading volume in agriculture futures markets is consistent with the results

reached by Yang et al. (2001) for storable commodities (such as corn. oats, soybeans, wheat, cotton and pork bellies), and non- storable commodities (such as hogs, live cattle, feeder cattle).

The error-correction terms $\mathrm{EC}_{\mathrm{t}}(e c m(-1))$ represent the speeds of adjustment in the shortrun to restore deviations from the long-run equilibrium. A negative and significant term signifies that a certain variable is error-correcting in the sense that it returns to its long-run equilibrium after deviating from it. The results in Table 5 indicate that the $\mathrm{EC}_{\mathrm{t}}$ term in the equation for oil 
prices is negative and significant implying an adjustment process. However, the adjustment is relatively slower due to the smaller coefficient estimated for the $\mathrm{EC}_{\mathrm{t}}$ term.

Tables 6 and 7 report the long-run and short-run estimates, respectively, for the gasoline price. The long-run estimates in Table 6 suggest that only the impact on the gasoline price in the long-run comes from the oil price, and that this impact is positive and significant. This is consistent with the traditional view as oil cost represents more than $50 \%$ of the total gasoline cost. None of the other endogenous variables has a significant impact on gasoline prices in the long-run. This result suggests that the gasoline price is influenced by factors related to the oil markets in the long-run. Ethanol price is still not influential in the long run as it is constrained by regulatory and institutional walls, particularly the blending wall.

On the other hand, just as in the case for the oil price, there is a significant relationship between gasoline prices and the cross-market lagged trading volumes of ethanol and soybeans, $V M E$ and $V M S B$, in the long-run, and no impact outsourced from open interest of any of the grain commodities. However, the cross- trading volume signs of the impacts of ethanol and soybeans on gasoline have been reversed relative to their impacts on the oil price. Here, the impact of $V M E$ is positive and that of $V M S B$ is negative. In the short-run, there is a significant impact of corn, ethanol, and oil prices on gasoline prices (Table 7). This short-run result matches, to some extent, the conventional view of the chain order in the energy-grain nexus.

\section{[Tables 6 and 7 go here]}

The results for equation of the thinly-traded ethanol, somewhat surprisingly, indicate that no significant relationships between the variables are detected in the long-run (Table 8). Even though the bounds testing procedure indicates the presence of a long-run forcing /dependent 
variable relationship when ethanol is the dependent variable, a significant long-run relationship has not been estimated with the finite sample. Tyner (2010) found a strengthening long-run relationship between prices of oil, gasoline, ethanol and corn in late 2008 and 2009, as ethanol production came under severe pressure, leading to a causal relationship originating from corn to ethanol prices. Ethanol has been shackled by the blending wall, over-capacity and infrastructure problems.

\section{[Table 8 goes here]}

However, the short-run results for ethanol demonstrate that all of the endogenous variables (namely oil, gasoline, corn, soybeans and sugar) and the exogenous OIE have significant impacts on ethanol prices, with the open interest OIE having a negative effect (Table 9). This is consistent with the assertion in Tyner (2010) that ethanol strengthened its relationship with other commodities in 2008-2009. It is interesting to see that the ethanol return is sensitive to its small open interest, but not to its thin trading volume or those of the other grains, which is not surprising. This finding is weakly consistent with the results provided by Dahlgran (2009). Ethanol is known to be thinly traded and its hedgers and speculators do not trust its market, so they hedge and speculate in other markets. The negative relationship with open interest also indicates active arbitrage activity in the ethanol market.

\section{[Table 9 goes here]}

\section{Generalized Variance Decomposition and Impulse Response Analysis}

The generalized forecast error variance decompositions (GVD) developed by Koop et al. (1996) and Pesaran and Shin (1998) capture how much of the variance of a particular variable 
can be explained by another variable in the same system of a VAR. Unexpected shocks to an individual variable can affect both the variable itself and the other variables in the model. On the other hand, the generalized impulse responses (GIRF) show the dynamic responses of a variable to shocks in its own and other variables in the VAR. Both methods are based on the estimation of the moving average representation of the original VAR, and the results are not sensitive to the order of variables entering into the system.

The results of the generalized forecast-error variance decompositions for the full period are reported in Table 10. The results indicate that there is a strong relationship between the variables, except for sugar returns. Relatively speaking, the response of the variables to the sugar returns or the response of the sugar to the other variables is smaller. On the other hand, the strongest results are obtained for the relationship between oil and gasoline returns, which is expected. As indicated in Panels C and D of Table 10, the oil and gasoline returns can explain approximately 82 percent of the variations in each other. The ethanol returns account for approximately 20 and 22 percent variation in gasoline and oil returns, respectively. The impact of oil and gasoline returns on ethanol returns (Panel B) is symmetrical, with the impacts of gasoline and oil on ethanol prices being around 20 and 22 percent, respectively.

\section{[Table 10 goes here]}

The GIRF results indicate ${ }^{3}$ that all the impulse response trajectories are similar, but the differences are in the relativity of the adjustments. We can summarize the results in the following points. The initial impacts of shocks in all variables are positive and significant. The impacts die out quickly, mostly by the beginning of the second horizon. There are several reasons that

\footnotetext{
${ }^{3}$ Due to space limitations, the GIRF results are not shown, but are available on request.
} 
explain this short-lived response. It is possible that most of the shocks in the period under consideration have been transient in nature, such as weather condition, fires and geopolitical fear. It may also be the case that consumers adapt quickly to these shocks even if they are related to aggregate demand, as happened in 2008. It is also possible that short-term macroeconomic factors, such as changes in exchange rates, overwhelm the shocks.

The strongest responses are usually to the "own" shocks, and to oil and gasoline returns. The most interesting results are the response of corn and sugar returns to the unexpected shocks in oil and gasoline returns. This finding has perhaps some bearing on the fact that both corn and sugar are used to derive bio-fuel gasoline, In both cases, the initial response of corn and sugar prices to the oil and gasoline shocks is positive and significant, implying that a flowing tide moves all the boats in the same direction. This IRF result is consistent with the short-run results obtained from the VEC models.

\section{Empirical Results for the Recovery Subperiod}

The 2007-2009 financial crisis plunged the world into what has been termed the Great Recession, which is officially dated to start from December 2007 and end in June 2009. This post-recession subperiod is the Recovery Period, which starts in July 2009 and goes to January 13,2011 , which is the end of the sample period. ${ }^{4}$

The calculated F-statistics for this subperiod show that there is only one cointegrating relationship among the six variables, using the information criteria, compared with three CEs for the full sample (Table 11). This relationship has ethanol as the dependent variable and the prices

\footnotetext{
${ }^{4}$ Changing this period does not lead to different cointegration results in the empirical analysis.
} 
of oil, RPOP gasoline, corn, ethanol, sugar and soybeans as the forcing variables. In contrast, the full period has long-run relationships for oil and gasoline, as well as for ethanol. This main result suggests that the long-run relationships between the variables have weakened and the system has become less stable in the Recovery Period, compared with the full period, because it has more common stochastic shocks. Even the optimal lag was shortened significantly in the subperiod, compared with the lag length in the full period.

\section{[Table 11 goes here]}

The ethanol open-interest position in its own equation under the subperiod is positive in the long-run, indicating money inflows in the ethanol futures market in the 2009-2010 Recovery Period. This result was not significant in the full period. The subperiod also shows cross-market trading volume impact from sugar volume to ethanol price. This is different from the full period, where the trading volume was from ethanol and soybeans on the oil, gasoline and ethanol prices.

\section{[Tables 12 and 13 go here]}

\section{Conclusions}

The conventional view of the causal ordering within the energy-grain price nexus states that the casual relationships flows from the price of oil to the prices of gasoline, ethanol, and corn, and then on to other grains which share the same cropland. As far as the causal ordering of this nexus is concerned, the empirical results are mixed in the long run over the full sample. They show that oil is influenced by gasoline and soybean prices, which is not consistent with the conventional view of oil prices. The results are, however, consistent for the gasoline price, which 
has been shown to be influenced by the oil price over the long run. Ethanol shows no sensitivity to any of the prices in the long run, so that the result is not consistent with the conventional view.

These results show that oil and ethanol prices face different long-term driving forces, which provide diverse long-term substitution opportunities between gasoline and ethanol. However, this finding is still conditional on the institutional walls that confine the development of ethanol as an alternative fuel.

The relationships between the prices in the short run are more aligned with the conventional view. These prices influence each other more in feedback relationships than in a unidirectional influence, suggesting that these commodity prices share short-run common shocks. Substitution among oil, gasoline and ethanol is thus not very useful in the short run. Any green energy policy may not be successful in reducing energy prices, as it may have greater bearing on national security.

The estimates also suggests that the trading volume, and not the open interest, are significant in the long run, a result that holds for some of the commodities, implying these variables are important for improving the forecasts of futures prices. This result also implies that market liquidity dominates market depth in influencing long-term pricing, and that speculators are dominant over arbitrageurs in these markets. There are own-market and cross-market trading volume impacts of ethanol and soybeans on the oil, gasoline and ethanol prices. The sign of the trading volume impacts for ethanol and soybeans alternate in affecting oil, gasoline and ethanol returns, suggesting that two hypotheses, namely the irrational liquidity premium and simultaneous arrival of new information to volumes and prices, hold for these commodities. 
Open interest is only significant for ethanol and is negative, implying that there is money outflow from the ethanol market and active arbitrage activity in this market. The results also indicate that there is money inflow from the ethanol markets to the gasoline market. The shortrun results for the trading volume and open interest are similar in the short run as in the long run. It is somewhat surprising that the volume and open interest of sugar and corn have no lead/lag relationships with oil, gasoline and ethanol prices and returns.

The most interesting IRF results are the responses of corn and sugar returns to the unexpected shocks in oil and gasoline returns. This finding is likely to have some bearing on the fact that both corn and sugar are used to derive bio-fuel gasoline.

The subperiod which coincides with the economic recovery that started in July 2009 shows less of a long-run equilibrium relationship and more of common stochastic shocks in the energy and grain prices. This underscores the changes that the US economy and commodity markets have undergone during the 2007-2009 Great Recession. 


\section{References}

Admati, A.R. and Pfleiderer, P. (1988). A theory of intraday patterns: Volume and price variability. Review of Financial Studies 1, 3-40.

Baffes, J. and Haniotis, T. (2010). Placing the 2006/08 commodity price boom into perspective. Policy Research Working Paper 5371, World Bank. http://wwwwds.worldbank.org/external/default/WDSContentServer/IW3P/IB/2010/07/21/000158349_2010 0721110120/Rendered/PDF/WPS5371.pdf.

Dahlgran, R.A. (2009). Inventory and transformation hedging effectiveness in corn crushing. Journal of Agricultural and Resource Economics 34, 154-171.

Dahlgran, R.A. (2010). Ethanol futures: Thin but effective? Why? Proceedings of the NCCC-134 Conference on Applied Commodity Price Analysis, Forecasting and Market Risk Management. Saint Louis, Missouri. http://www.farmdoc.illinois.edu/nccc134.

Franken, J.R.V. and Parcell, J.L. (2003) Cash ethanol cross-hedging opportunities. Journal of Agricultural and Applied Economics 35, 509-516.

Garbade, K. and Silber, W.L. (1982). Price movements and price discovery in futures and cash markets. Review of Economics and Statistics 64, 289-297.

Ghatak S. and Siddiki, J. (2001). The use of ARDL approach in estimating virtual exchange rates in India. Journal of Applied Statistics, 28: 573-583. 
Gohin A and Treguer D. (2010). On the (De)Stabilization Effects of Biofuels: Relative Contributions of Policy Instruments and Market Forces. Journal of Agricultural and Resource Economics 35, 72-86.

Kyle. A. S .(1985). Continuous auctions and insider trading. Econometrica 53 (6), 1315-1335

Laurenceson, J. and Chai, J.C. H. (2003). Financial Reform and Economic Development in China, Cheltenham, UK, Edward Elgar.

Lin, W. and Riley, P.A. (1998). Rethinking the soybeans-to-corn price ratio. Is it still a good indicator for planting decisions? Economic Research Service, US Department of Agriculture, Washington, D,C., April, 1-33.

http://www.ers.usda.gov/publications/corn/crnprato.pdf

Mattos, F. and Garica, P. (2004). Price discovery in thinly traded markets: Cash and futures relationships in Brazilian agricultural futures markets. Proceedings of the NCCC-134 Conference on Applied Commodity Price Analysis, Forecasting and Market Risk Management. Saint Lois, Missouri. http://ageconsearch.umn.edu/bitstream/19019/1/cp04ma02.pdf

Pesaran, M.H. and Pesaran, B. (1997). Working with Microfit 4.0. Cambridge: Camfit Data Ltd.

Pesaran, M.H., Shin, Y. and Smith, R. J. (2001). Bounds testing approaches to the analysis of level relationships, Journal of Applied Econometrics, 16, 289-326.

Stock, J.H. and Watson, M.W. (2003). Introduction to Econometrics, Boston: Addison Wesley, page 460 .

Tokgoz, S., Elobeid, A. Fabiose, J., Hayes, D.J., Babcock, B.A., Yu, T.H. and Dong, F.X. 
(2008). Bottlenecks, drought, and oil price spikes: Impact on U.S ethanol and agricultural sectors. Review of Agricultural Economics 30, 604-622

Tyner, W.E. (2008). The US ethanol and biofuels boom: its origin, current status and future prospect. BioScience 58, 646-653.

Tyner, W.E. (2010). The integration of energy and agricultural markets. Agricultural Economics 41, 193-201.

Wang, H.H. and Ke, B. (2002). Efficiency test of agricultural commodity futures markets in China." Washington State University. http://www.bm.ust.hk/ ced/Holly\%20H\%20WANG.pdf

Yang, J., Bessler, D.A. and Leathan, D. (2001). Asset storability and price discovery in commodity futures market: A new look. Journal of Futures Markets 21, 279-300.

Zapato, H.O., Fortenberry, T.R. and Armstrong, D. (2003). Price discovery in the futures and cash market for sugar. Paper presented at the Southern Agricultural Economics Association Annual Meeting, Mobile, Alabama, February, 1-5.

Zapato, H.O., Fortenberry, T.R. and Armstrong, D. (2005). Price discovery in the world sugar futures and cash markets: Implications for the Dominican Republic. Staff Paper \#469, University of Wisconsin, Madison, Wisconsin.

http://www.aae.wisc.edu/pubs/sps/pdf/stpap469.pdf 


\section{Table 1: Descriptive Statistics for Returns}

Panel A: Energy and Grain Prices

\begin{tabular}{|c|c|c|c|c|c|c|}
\hline & $\triangle \mathrm{LFC}$ & $\Delta \mathrm{LFE}$ & $\Delta \mathrm{LFG}$ & $\triangle \mathrm{LFO}$ & $\Delta \mathrm{LFS}$ & $\triangle \mathrm{LFSB}$ \\
\hline Mean & 0.003244 & -0.001061 & 0.000277 & 0.000401 & 0.000138 & 0.006936 \\
\hline Maximum & 0.362500 & 0.196000 & 0.222000 & 0.244762 & 0.017400 & 0.707500 \\
\hline Minimum & -0.300000 & -0.493000 & -0.243000 & -0.233095 & -0.034500 & -1.445000 \\
\hline Std. Dev. & 0.095031 & 0.044404 & 0.047313 & 0.042362 & 0.004626 & 0.198935 \\
\hline Skewness & -0.082839 & -1.819118 & -0.249709 & -0.172735 & -1.030655 & -0.637570 \\
\hline Kurtosis & 4.513055 & 18.61072 & 5.605919 & 6.076662 & 11.83425 & 7.360735 \\
\hline Jarque-Bera & 116.4184 & 12910.79 & 353.7716 & 481.6562 & 4135.223 & 1037.260 \\
\hline Probability & 0.000000 & 0.000000 & 0.000000 & 0.000000 & 0.000000 & 0.000000 \\
\hline Sum Sq. Dev. & 10.88215 & 2.375909 & 2.697407 & 2.162391 & 0.025783 & 47.68822 \\
\hline
\end{tabular}

Notes: Full sample. The full period is May 31, 2006-January 13, 2011. Returns are the logarithmic differences of futures prices. $F C$ stands for corn, $F E$ for ethanol, $F G$ for gasoline, $F O$ for oil, $F S$ for sugar and $F S B$ for soybeans 
Table 1: Cont.

Paper B: Open Interest and Trading Volumes

\begin{tabular}{lcrrrrrrr}
\hline & \multicolumn{1}{c}{$\Delta \mathrm{LOIC}$} & \multicolumn{1}{c}{$\Delta$ LOIE } & \multicolumn{1}{c}{$\Delta$ LOIS } & \multicolumn{1}{c}{$\Delta$ LOISB } & \multicolumn{1}{c}{$\Delta$ LVMC } & \multicolumn{1}{c}{$\Delta$ LVME } & \multicolumn{1}{c}{$\Delta \mathrm{LVMS}$} & $\Delta \mathrm{LVMSB}$ \\
\hline Mean & 198.9934 & 6.179104 & 107.4320 & 210.0970 & 159.0050 & 0.737977 & 6.676617 & 95.51824 \\
Maximum & 43979.00 & 777.0000 & 34808.00 & 48003.00 & 390713.0 & 1722.000 & 143776.0 & 236795.0 \\
Minimum & -53938.00 & -957.0000 & -42682.00 & -44711.00 & -258025.0 & -1690.000 & -179224.0 & -170274.0 \\
Std. Dev. & 9939.738 & 112.3647 & 7287.676 & 5663.678 & 63217.67 & 222.8061 & 36573.05 & 31508.70 \\
Skewness & -0.389413 & -1.688108 & -0.665434 & -0.389222 & 0.448775 & -0.054230 & -0.080097 & 0.609532 \\
Kurtosis & 6.407069 & 21.06908 & 7.410129 & 11.56701 & 7.588228 & 14.66139 & 4.750780 & 8.804596 \\
Jarque-Bera & 613.7879 & 16979.01 & 1066.327 & 3718.481 & 1098.336 & 6833.993 & 155.3174 & 1767.768 \\
Probability & 0.000000 & 0.000000 & 0.000000 & 0.000000 & 0.000000 & 0.000000 & 0.000000 & 0.000000 \\
Sum Sq. Dev. & $1.19 \mathrm{E}+11$ & 15214121 & $6.40 \mathrm{E}+10$ & $3.87 \mathrm{E}+10$ & $4.82 \mathrm{E}+12$ & 59819287 & $1.61 \mathrm{E}+12$ & $1.20 \mathrm{E}+12$ \\
\hline
\end{tabular}

Notes: Full sample. All variables are logarithmic differences. OIC, OIE, OIS and OISB are open interest for corn, ethanol, sugar and soybeans, respectively. $V M C, V M E, V M S$ and $V M S B$ are trading volumes for corn, ethanol, sugar and soybeans, respectively. 
Table 2: Unit Root Test Results

\begin{tabular}{|c|c|c|c|c|}
\hline & \multicolumn{2}{|c|}{ ADF } & \multicolumn{2}{|c|}{ PP } \\
\hline \multicolumn{5}{|l|}{ A.Levels } \\
\hline & Intercept & $\begin{array}{c}\text { Intercept and } \\
\text { Trend }\end{array}$ & Intercept & $\begin{array}{c}\text { Intercept and } \\
\text { Trend }\end{array}$ \\
\hline LFC & -1.547 & -1.547 & -1.606 & -1.734 \\
\hline LFE & $-3.165^{* *}$ & -2.795 & $-3.260 *$ & -2.772 \\
\hline LFG & -1.870 & -1.870 & -1.709 & -1.672 \\
\hline LFO & -1.513 & -1.563 & -1.527 & -1.579 \\
\hline LFS & -0.251 & -2.407 & -0.155 & -2.347 \\
\hline LFSB & -1.584 & -1.720 & -1.609 & -1.758 \\
\hline LOIC & -1.084 & -0.731 & -1.002 & -0.596 \\
\hline LOIE & -0.596 & -2.010 & -1.169 & -2.095 \\
\hline LOIS & -2.338 & -2.094 & -2.074 & -2.338 \\
\hline LOISB & -1.464 & -1.607 & -1.274 & -1.421 \\
\hline LVMC & $-2.945^{* *}$ & $-4.149 *$ & $-7.284 *$ & $-10.641 *$ \\
\hline LVME & -0.980 & $-4.870 * *$ & $-14.465^{*}$ & $-32.143^{*}$ \\
\hline LVMS & $-6.867 *$ & $-7.494 *$ & $-17.421 *$ & $-18.543^{*}$ \\
\hline LVMSB & $-3.292 *$ & $-5.810 *$ & $-9.711 *$ & $-14.186^{*}$ \\
\hline \multicolumn{5}{|c|}{ B. First Differences } \\
\hline & Intercept & $\begin{array}{c}\text { Intercept and } \\
\text { Trend } \\
\end{array}$ & Intercept & $\begin{array}{c}\text { Intercept and } \\
\text { Trend }\end{array}$ \\
\hline LFC & $-33.846^{*}$ & $-33.832 *$ & $-33.846^{*}$ & $-33.832 *$ \\
\hline LFG & $-14.886^{*}$ & $-14.899 *$ & $-35.676^{*}$ & $-35.675^{*}$ \\
\hline LFO & $-15.736^{*}$ & $-15.734 *$ & $-36.323 *$ & $-36.311 *$ \\
\hline LFS & $-34.889 *$ & $-34.955^{*}$ & $-34.924 *$ & $-35.017 *$ \\
\hline LFSB & $-33.824 *$ & $-33.812 *$ & $-33.821 *$ & $-33.809 *$ \\
\hline LOIC & $-10.868 *$ & $-10.956^{*}$ & $-29.718 *$ & $-29.686^{*}$ \\
\hline LOIE & $-9.800 *$ & $-9.777 *$ & $-48.652 *$ & $-48.697 *$ \\
\hline LOIS & $-10.592 *$ & $-10.671 *$ & $-30.762 *$ & $-30.635^{*}$ \\
\hline LOISB & $-11.246^{*}$ & $-11.255^{*}$ & $-31.708 *$ & $-31.696^{*}$ \\
\hline
\end{tabular}

Note: Full sample. $(*)$ and $(* *)$ denote $1 \%$ and $5 \%$ significance levels, respectively. 
Table 3: Bounds-Testing Procedure Results

\begin{tabular}{lc}
\hline Cointegration hypotheses & F-statistics \\
\hline $\mathrm{F}\left(\mathrm{LFSB}_{\mathrm{t}} \mid \mathrm{LFS}_{\mathrm{t}}, \mathrm{LFO}_{\mathrm{t}}, \mathrm{LFG}_{\mathrm{t}}, \mathrm{LFE}_{\mathrm{t}}, \mathrm{LFC}_{\mathrm{t}}\right)$ & 2.734 \\
$\mathrm{~F}\left(\mathrm{LFS}_{\mathrm{t}} \mid \mathrm{LFSB}_{\mathrm{t}}, \mathrm{LFO}_{\mathrm{t}}, \mathrm{LFG}_{\mathrm{t}}, \mathrm{LFE}_{\mathrm{t}}, \mathrm{LFC}_{\mathrm{t}}\right)$ & 2.246 \\
$\mathrm{~F}\left(\mathrm{LFO}_{\mathrm{t}} \mid \mathrm{LFS}_{\mathrm{t}}, \mathrm{LFSB}_{\mathrm{t}}, \mathrm{LFG}_{\mathrm{t}}, \mathrm{LFE}_{\mathrm{t}}, \mathrm{LFC}_{\mathrm{t}}\right)$ & $3.707 * * *$ \\
$\mathrm{~F}\left(\mathrm{LFG}_{\mathrm{t}} \mid \mathrm{LFS}_{\mathrm{t}}, \mathrm{LFO}_{\mathrm{t}}, \mathrm{LFSB}_{\mathrm{t}}, \mathrm{LFE}_{\mathrm{t}}, \mathrm{LFC}_{\mathrm{t}}\right)$ & $3.833^{* *}$ \\
$\mathrm{~F}\left(\mathrm{LFE}_{\mathrm{t}} \mid \mathrm{LFS}_{\mathrm{t}}, \mathrm{LFO}_{\mathrm{t}}, \mathrm{LFG}_{\mathrm{t}}, \mathrm{LFSB}_{\mathrm{t}}, \mathrm{LFC}_{\mathrm{t}}\right)$ & $3.766^{* * *}$ \\
$\mathrm{~F}\left(\mathrm{LFC}_{\mathrm{t}} \mid \mathrm{LFS}_{\mathrm{t}}, \mathrm{LFO}_{\mathrm{t}}, \mathrm{LFG}_{\mathrm{t}}, \mathrm{LFE}_{\mathrm{t}}, \mathrm{LFSB}_{\mathrm{t}}\right)$ & 2.220 \\
\hline $\begin{array}{l}\text { Notes: Full sample. The full sample covers the period May 31, 2006 -January 13, 2011. Lag length is 6, as } \\
\text { suggested by the LR test. }\end{array}$
\end{tabular}


Table 4: Estimated Long-Run Coefficients using the ARDL Approach (ARDL(3,3,4,6,1,1) based on AIC, Dependent variable is LFO)

\begin{tabular}{lccc}
\hline Regressor & Coefficient & T-Ratio & Prob \\
\hline LFC & -0.316 & -1.894 & 0.059 \\
LFE & -0.074 & -0.516 & 0.606 \\
LFG & 1.130 & 9.311 & 0.000 \\
LFS & -0.035 & -0.493 & 0.622 \\
LFSB & 0.395 & 1.934 & 0.053 \\
C & -1.456 & -0.483 & 0.630 \\
L1LOIC & -0.008 & -0.045 & 0.964 \\
L1LOIE & 0.005 & 0.113 & 0.910 \\
L1LOIS & -0.051 & -0.412 & 0.680 \\
L1LOISB & 0.087 & 0.583 & 0.560 \\
L1LVMC & 0.024 & 0.693 & 0.488 \\
L1LVME & -0.030 & -1.808 & 0.071 \\
L1LVMS & -0.038 & -1.189 & 0.235 \\
L1LVMSB & 0.063 & 1.777 & 0.076 \\
\hline
\end{tabular}

Note: Full sample. 
Table 5: Error-Correction Representation for the Selected ARDL Model

(ARDL $(3,3,4,6,1,1)$ based on AIC, Dependent variable is $\triangle \mathrm{LFO}$ )

\begin{tabular}{|c|c|c|c|}
\hline Regressor & Coefficient & T-Ratio & Prob \\
\hline$\Delta \mathrm{LFO} 1$ & 0.016 & 0.565 & 0.572 \\
\hline$\triangle \mathrm{LFO} 2$ & -0.076 & -2.696 & 0.007 \\
\hline$\triangle \mathrm{LFC}$ & 0.026 & 1.448 & 0.148 \\
\hline$\Delta \mathrm{LFC} 1$ & -0.004 & -0.270 & 0.787 \\
\hline$\triangle \mathrm{LFC} 2$ & 0.048 & 3.053 & 0.002 \\
\hline$\Delta \mathrm{LFE}$ & 0.039 & 2.136 & 0.033 \\
\hline$\triangle \mathrm{LFE} 1$ & 0.000 & -0.010 & 0.992 \\
\hline$\triangle \mathrm{LFE} 2$ & -0.044 & -2.416 & 0.016 \\
\hline$\triangle \mathrm{LFE} 3$ & 0.026 & 1.557 & 0.120 \\
\hline$\Delta \mathrm{LFG}$ & 0.804 & 56.037 & 0.000 \\
\hline$\Delta \mathrm{LFG} 1$ & -0.022 & -0.800 & 0.424 \\
\hline$\Delta \mathrm{LFG} 2$ & 0.044 & 1.620 & 0.105 \\
\hline$\Delta \mathrm{LFG} 3$ & -0.037 & -2.672 & 0.008 \\
\hline$\Delta \mathrm{LFG} 4$ & -0.045 & -3.595 & 0.000 \\
\hline$\triangle \mathrm{LFG5}$ & -0.044 & -3.509 & 0.000 \\
\hline$\Delta \mathrm{LFS}$ & 0.032 & 2.540 & 0.011 \\
\hline$\triangle \mathrm{LFSB}$ & 0.089 & 3.948 & 0.000 \\
\hline $\mathrm{C}$ & -0.035 & -0.489 & 0.625 \\
\hline$\Delta \mathrm{L} 1 \mathrm{LOIC}$ & 0.000 & -0.045 & 0.964 \\
\hline$\Delta \mathrm{L} 1 \mathrm{LOIE}$ & 0.000 & 0.113 & 0.910 \\
\hline$\Delta \mathrm{L} 1 \mathrm{LOIS}$ & -0.001 & -0.411 & 0.681 \\
\hline$\Delta \mathrm{L} 1 \mathrm{LOISB}$ & 0.002 & 0.608 & 0.544 \\
\hline$\Delta \mathrm{L} 1 \mathrm{LVMC}$ & 0.001 & 0.700 & 0.484 \\
\hline$\triangle \mathrm{L} 1 \mathrm{LVME}$ & -0.001 & -1.878 & 0.061 \\
\hline$\Delta \mathrm{L} 1 \mathrm{LVMS}$ & -0.001 & -1.153 & 0.249 \\
\hline$\Delta \mathrm{L} 1 \mathrm{LVMSB}$ & 0.002 & 1.920 & 0.055 \\
\hline $\operatorname{ecm}(-1)$ & -0.024 & -4.764 & 0.000 \\
\hline
\end{tabular}

Note: Full sample. 
Table 6: Estimated Long-Run Coefficients using the ARDL Approach (ARDL(3,3,4,6,0,0) based on AIC, Dependent variable is LFG)

\begin{tabular}{lccc}
\hline Regressor & Coefficient & T-Ratio & Prob \\
\hline LFC & 0.223 & 1.251 & 0.211 \\
LFE & 0.159 & 1.134 & 0.257 \\
LFO & 0.649 & 5.751 & 0.000 \\
LFS & 0.091 & 1.150 & 0.251 \\
LFSB & -0.146 & -0.671 & 0.503 \\
C & -0.503 & -0.165 & 0.869 \\
L1LOIC & 0.112 & 0.602 & 0.547 \\
L1LOIE & -0.024 & -0.566 & 0.571 \\
L1LOIS & 0.118 & 0.933 & 0.351 \\
L1LOISB & -0.108 & -0.684 & 0.494 \\
L1LVMC & -0.030 & -0.831 & 0.406 \\
L1LVME & 0.034 & 1.925 & 0.055 \\
L1LVMS & 0.024 & 0.729 & 0.466 \\
L1LVMSB & -0.064 & -1.670 & 0.095
\end{tabular}

Note: Full sample. 
Table 7: Error-Correction Representation for the Selected ARDL Model (ARDL $(3,3,4,6,0,0)$ based on AIC, Dependent variable is $\Delta \mathrm{LFG})$

\begin{tabular}{|c|c|c|c|}
\hline Regressor & Coefficient & T-Ratio & Prob \\
\hline$\Delta \mathrm{LFG1}$ & 0.035 & 1.202 & 0.230 \\
\hline$\Delta \mathrm{LFG} 2$ & -0.054 & -1.892 & 0.059 \\
\hline$\Delta \mathrm{LFC}$ & -0.010 & -0.575 & 0.566 \\
\hline$\triangle \mathrm{LFC} 1$ & 0.008 & 0.508 & 0.611 \\
\hline$\triangle \mathrm{LFC} 2$ & -0.057 & -3.468 & 0.001 \\
\hline$\Delta \mathrm{LFE}$ & 0.047 & 2.455 & 0.014 \\
\hline$\Delta \mathrm{LFE} 1$ & -0.022 & -1.138 & 0.255 \\
\hline$\triangle \mathrm{LFE} 2$ & 0.044 & 2.297 & 0.022 \\
\hline$\triangle \mathrm{LFE} 3$ & -0.037 & -2.088 & 0.037 \\
\hline$\Delta \mathrm{LFO}$ & 0.908 & 58.962 & 0.000 \\
\hline$\triangle \mathrm{LFO} 1$ & -0.028 & -0.949 & 0.343 \\
\hline$\triangle \mathrm{LFO} 2$ & 0.096 & 3.212 & 0.001 \\
\hline$\triangle \mathrm{LFO} 3$ & 0.046 & 3.090 & 0.002 \\
\hline$\Delta \mathrm{LFO} 4$ & 0.059 & 4.288 & 0.000 \\
\hline$\triangle \mathrm{LFO5}$ & 0.033 & 2.401 & 0.016 \\
\hline$\Delta \mathrm{LFS}$ & 0.002 & 1.281 & 0.201 \\
\hline$\Delta \mathrm{LFSB}$ & -0.004 & -0.670 & 0.503 \\
\hline $\mathrm{C}$ & -0.012 & -0.162 & 0.871 \\
\hline$\Delta \mathrm{L} 1 \mathrm{LOIC}(-1)$ & 0.003 & 0.605 & 0.545 \\
\hline$\Delta \operatorname{L} 1 \operatorname{LOIE}(-1)$ & -0.001 & -0.574 & 0.566 \\
\hline$\Delta \operatorname{L} 1 \operatorname{LOIS}(-1)$ & 0.003 & 0.904 & 0.366 \\
\hline$\Delta \operatorname{L1LOISB}(-1)$ & -0.003 & -0.727 & 0.467 \\
\hline$\triangle \mathrm{L} 1 \mathrm{LVMC}(-1)$ & -0.001 & -0.846 & 0.397 \\
\hline$\triangle \mathrm{L} 1 \mathrm{LVME}(-1)$ & 0.001 & 2.034 & 0.042 \\
\hline$\Delta \operatorname{L1LVMS}(-1)$ & 0.001 & 0.713 & 0.476 \\
\hline$\Delta \operatorname{L1LVMSB}(-1)$ & -0.002 & -1.892 & 0.059 \\
\hline $\operatorname{ecm}(-1)$ & -0.024 & -4.121 & 0.000 \\
\hline
\end{tabular}

Note: Full sample. 
Table 8. Estimated Long-Run Coefficients using the ARDL Approach (ARDL $(4,1,5,5,1,2)$ based on AIC, Dependent variable is LFE)

\begin{tabular}{lccc}
\hline Regressor & Coefficient & T-Ratio & Prob \\
\hline LFC & 0.520 & 1.623 & 0.105 \\
LFO & 0.214 & 0.512 & 0.609 \\
LFG & 0.099 & 0.227 & 0.820 \\
LFS & 0.177 & 1.523 & 0.128 \\
LFSB & -0.238 & -0.569 & 0.570 \\
C & 1.786 & 0.318 & 0.750 \\
L1LOIC & -0.015 & -0.043 & 0.966 \\
L1LOIE & -0.148 & -2.102 & 0.036 \\
L1LOIS & -0.029 & -0.121 & 0.904 \\
L1LOISB & 0.080 & 0.282 & 0.778 \\
L1LVMC & 0.009 & 0.131 & 0.896 \\
L1LVME & 0.039 & 1.211 & 0.226 \\
L1LVMS & -0.045 & -0.718 & 0.473 \\
L1LVMSB & -0.021 & -0.335 & 0.738 \\
\hline
\end{tabular}

Note: Full sample. 
Table 9. Error-Correction Representation for the Selected ARDL Model (ARDL $(4,1,5,5,1,2)$ based on AIC, Dependent variable is $\triangle \mathrm{LFE})$

\begin{tabular}{|c|c|c|c|}
\hline Regressor & Coefficient & T-Ratio & Prob \\
\hline$\triangle \mathrm{LFE} 1$ & 0.048 & 1.711 & 0.087 \\
\hline$\triangle \mathrm{LFE} 2$ & 0.070 & 2.601 & 0.009 \\
\hline$\triangle \mathrm{LFE} 3$ & 0.092 & 3.422 & 0.001 \\
\hline$\Delta \mathrm{LFC}$ & 0.235 & 8.313 & 0.000 \\
\hline$\Delta \mathrm{LFO}$ & 0.098 & 2.129 & 0.033 \\
\hline$\Delta \mathrm{LFO} 1$ & 0.066 & 1.456 & 0.146 \\
\hline$\triangle \mathrm{LFO} 2$ & 0.069 & 1.537 & 0.125 \\
\hline$\Delta \mathrm{LFO} 3$ & -0.091 & -2.042 & 0.041 \\
\hline$\triangle \mathrm{LFO} 4$ & 0.116 & 2.608 & 0.009 \\
\hline$\Delta \mathrm{LFG}$ & 0.103 & 2.353 & 0.019 \\
\hline$\Delta \mathrm{LFG} 1$ & -0.068 & -1.576 & 0.115 \\
\hline$\Delta \mathrm{LFG} 2$ & -0.102 & -2.362 & 0.018 \\
\hline$\Delta \mathrm{LFG} 3$ & 0.074 & 1.717 & 0.086 \\
\hline$\Delta \mathrm{LFG} 4$ & -0.071 & -1.642 & 0.101 \\
\hline$\Delta \mathrm{LFS}$ & 0.038 & 1.873 & 0.061 \\
\hline$\triangle \mathrm{LFSB}$ & 0.165 & 4.622 & 0.000 \\
\hline$\Delta \mathrm{LFSB} 1$ & -0.047 & -1.518 & 0.129 \\
\hline $\mathrm{C}$ & 0.036 & 0.315 & 0.753 \\
\hline$\Delta \mathrm{L} 1 \mathrm{LOIC}$ & 0.000 & -0.043 & 0.966 \\
\hline$\Delta \mathrm{L} 1 \mathrm{LOIE}$ & -0.003 & -1.894 & 0.058 \\
\hline$\Delta \mathrm{L} 1 \mathrm{LOIS}$ & -0.001 & -0.121 & 0.904 \\
\hline$\Delta \mathrm{L} 1 \mathrm{LOISB}$ & 0.002 & 0.292 & 0.770 \\
\hline$\Delta \mathrm{L} 1 \mathrm{LVMC}$ & 0.000 & 0.131 & 0.896 \\
\hline$\Delta \mathrm{L} 1 \mathrm{LVME}$ & 0.001 & 1.283 & 0.200 \\
\hline$\Delta \mathrm{L} 1 \mathrm{LVMS}$ & -0.001 & -0.715 & 0.475 \\
\hline$\Delta \mathrm{L} 1 \mathrm{LVMSB}$ & 0.000 & -0.336 & 0.737 \\
\hline $\operatorname{ecm}(-1)$ & -0.020 & -3.622 & 0.000 \\
\hline
\end{tabular}

Note: Full sample. 
Table 10. Generalized Variance Decompositions

\begin{tabular}{ccccccc}
\hline Panel A & \multicolumn{7}{c}{} & & & \\
\hline Horizon & DLFC & DLFE & DLFG & DLFO & DLFS & DLFSB \\
0 & 1.000 & 0.308 & 0.124 & 0.164 & 0.072 & 0.365 \\
1 & 0.990 & 0.305 & 0.127 & 0.167 & 0.071 & 0.361 \\
2 & 0.987 & 0.304 & 0.127 & 0.167 & 0.072 & 0.362 \\
3 & 0.983 & 0.304 & 0.128 & 0.169 & 0.072 & 0.361 \\
4 & 0.971 & 0.300 & 0.131 & 0.170 & 0.075 & 0.356 \\
5 & 0.964 & 0.299 & 0.133 & 0.173 & 0.077 & 0.356 \\
\hline Panel B & & & & & \\
\hline Horizon & DLFC & DLFE & DLFG & DLFO & DLFS & DLFSB \\
0 & 0.308 & 1.000 & 0.200 & 0.221 & 0.048 & 0.233 \\
1 & 0.306 & 0.994 & 0.201 & 0.222 & 0.048 & 0.232 \\
2 & 0.306 & 0.990 & 0.201 & 0.221 & 0.048 & 0.231 \\
3 & 0.305 & 0.989 & 0.201 & 0.223 & 0.048 & 0.230 \\
4 & 0.304 & 0.979 & 0.205 & 0.229 & 0.048 & 0.228 \\
5 & 0.301 & 0.964 & 0.203 & 0.226 & 0.050 & 0.227 \\
\hline Panel C & & & & & DLFS & DLFSB \\
\hline Horizon & DLFC & DLFE & DLFG & DLFO & 0.033 & 0.185 \\
0 & 0.124 & 0.200 & 1.000 & 0.830 & 0.183 \\
1 & 0.123 & 0.202 & 0.995 & 0.827 & 0.033 & 0.183 \\
2 & 0.123 & 0.201 & 0.993 & 0.825 & 0.034 & 0.183 \\
3 & 0.123 & 0.200 & 0.990 & 0.822 & 0.035 & 0.183 \\
4 & 0.124 & 0.204 & 0.983 & 0.822 & 0.035 & 0.182 \\
5 & 0.125 & 0.202 & 0.967 & 0.809 & 0.039 & 0.179 \\
\hline Not & & & & &
\end{tabular}

Note: Full sample. 
Table 10. Generalized Variance Decompositions (Cont.)

\begin{tabular}{ccccccc}
\hline Panel D & \multicolumn{7}{c}{} & & & \\
\hline Horizon & DLFC & DLFE & DLFG & DLFO & DLFS & DLFSB \\
0 & 0.164 & 0.221 & 0.830 & 1.000 & 0.047 & 0.219 \\
1 & 0.163 & 0.223 & 0.826 & 0.995 & 0.047 & 0.218 \\
2 & 0.163 & 0.223 & 0.825 & 0.994 & 0.047 & 0.218 \\
3 & 0.164 & 0.222 & 0.822 & 0.990 & 0.048 & 0.219 \\
4 & 0.164 & 0.223 & 0.820 & 0.989 & 0.047 & 0.218 \\
5 & 0.164 & 0.219 & 0.807 & 0.973 & 0.051 & 0.215 \\
\hline Panel E & & & & & & \\
\hline Horizon & DLFC & DLFE & DLFG & DLFO & DLFS & DLFSB \\
0 & 0.072 & 0.048 & 0.033 & 0.047 & 1.000 & 0.049 \\
1 & 0.074 & 0.048 & 0.039 & 0.054 & 0.988 & 0.049 \\
2 & 0.075 & 0.048 & 0.039 & 0.054 & 0.986 & 0.049 \\
3 & 0.076 & 0.050 & 0.040 & 0.054 & 0.978 & 0.050 \\
4 & 0.076 & 0.050 & 0.040 & 0.054 & 0.976 & 0.050 \\
5 & 0.076 & 0.050 & 0.042 & 0.055 & 0.972 & 0.052 \\
\hline Panel F & & & & & DLFS & DLFSB \\
\hline Horizon & DLFC & DLFE & DLFG & DLFO & 0.049 & 1.000 \\
0 & 0.365 & 0.233 & 0.185 & 0.219 & 0.049 & 0.993 \\
1 & 0.363 & 0.233 & 0.185 & 0.221 & 0.050 & 0.989 \\
2 & 0.361 & 0.232 & 0.185 & 0.220 & 0.051 & 0.982 \\
3 & 0.359 & 0.234 & 0.185 & 0.223 & 0.056 & 0.963 \\
4 & 0.352 & 0.229 & 0.188 & 0.223 & 0.057 & 0.950 \\
\hline 5 & 0.351 & 0.227 & 0.186 & 0.220 & &
\end{tabular}


Table 11: Bounds-Testing Procedure Results (Subperiod)

\begin{tabular}{lc}
\hline \multicolumn{1}{c}{ Cointegration hypotheses } & F-statistics \\
\hline$F\left(L F S B_{t} \mid L F S_{t}, L F O_{t}, L F G_{t}, L F E_{t}, L F C_{t}\right)$ & 2.033 \\
$F\left(L F S_{t} \mid L F S B_{t}, L F O_{t}, L F G_{t}, L F E_{t}, L F C_{t}\right)$ & 2.032 \\
$F\left(L F O_{t} \mid L F S_{t}, L F S B_{t}, L F G_{t}, L F E_{t}, L F C_{t}\right)$ & 1.757 \\
$F\left(L F G_{t} \mid L F S_{t}, L F O_{t}, L F S B_{t}, L F E_{t}, L F C_{t}\right)$ & $4.177 * *$ \\
$F\left(L F E_{t} \mid L F S_{t}, L F O_{t}, L F G_{t}, L F S B_{t}, L F C_{t}\right)$ & 1.273 \\
$F\left(L F C_{t} \mid L F S_{t}, L F O_{t}, L F G_{t}, L F E_{t}, L F S B_{t}\right)$ &
\end{tabular}

Notes: The sample subperiod is the Recovery Period: 7/1/2009-1/13/2011, which followed the end of the 2007/2008 Great Recession that ended in June 2009. The lag length is 1 , as suggested by all criteria. ** denotes significance at the $5 \%$ level. 
Table 12. Estimated Long Run Coefficient (ARDL $(2,1,0,0,0,2)$ selected based by AIC, Dependent Variable $L F E$ )

\begin{tabular}{lccc}
\hline Regressor & Coefficient & T-Ratio & Prob \\
\hline LFC & 0.558 & 2.803 & 0.005 \\
LFG & -1.226 & -2.871 & 0.004 \\
LFO & 1.659 & 3.014 & 0.003 \\
LFS & 0.129 & 1.412 & 0.159 \\
LFSB & -0.697 & -2.783 & 0.006 \\
C & -3.287 & -0.708 & 0.480 \\
LOIC $(-1)$ & 0.126 & 0.615 & 0.539 \\
LOIE $(-1)$ & -0.141 & -1.926 & 0.055 \\
LOIS $(-1)$ & 0.167 & 0.877 & 0.381 \\
LOISB $(-1)$ & 0.236 & 1.064 & 0.288 \\
LVMC $(-1)$ & 0.009 & 0.283 & 0.777 \\
LVME $(-1)$ & -0.006 & -0.312 & 0.756 \\
LVMS $(-1)$ & -0.054 & -2.212 & 0.028 \\
LVMSB $(-1)$ & -0.046 & -1.227 & 0.221 \\
\hline
\end{tabular}

Note: The subperiod is the Recovery Period: 7/1/2009-1/13/2011 
Table 13. Error Correction Representation for the Selected ARDL Model $(\operatorname{ARDL}(\mathbf{2}, 1,0,0,0,2)$ selected based by AIC, Dependent Variable $\Delta \mathrm{LFE})$

\begin{tabular}{lccc}
\hline Regressor & Coefficient & T-Ratio & Prob \\
\hline$\Delta$ LFE1 & 0.107 & 2.538 & 0.012 \\
$\Delta$ LFC & 0.385 & 11.867 & 0.000 \\
$\Delta$ LFG & -0.084 & -3.132 & 0.002 \\
$\Delta$ LFO & 0.113 & 3.333 & 0.001 \\
$\Delta$ LFS & 0.009 & 1.464 & 0.144 \\
$\Delta$ LFSB & 0.161 & 4.060 & 0.000 \\
$\Delta$ LFSB 1 & -0.073 & -1.918 & 0.056 \\
C & -0.225 & -0.683 & 0.495 \\
$\Delta$ L1LOIC & 0.009 & 0.634 & 0.526 \\
$\Delta$ L1LOIE & -0.010 & -2.154 & 0.032 \\
$\Delta$ L1LOIS & 0.011 & 0.816 & 0.415 \\
$\Delta$ L1LOISB & 0.016 & 1.045 & 0.297 \\
$\Delta$ L1LVMC & 0.001 & 0.277 & 0.782 \\
$\Delta$ L1LVME & 0.000 & -0.310 & 0.757 \\
$\Delta$ L1LVMS & -0.004 & -2.170 & 0.031 \\
$\Delta$ L1LVMSB & -0.003 & -1.258 & 0.209 \\
ecm $(-1)$ & -0.068 & -4.377 & 0.000 \\
\hline Not & T & &
\end{tabular}

Note: The subperiod is the Recovery Period: 7/1/2009-1/13/2011 